\title{
A novel case of renal pathergy reaction in a Behçet's disease patient complicated by IgA vasculitis
}

\author{
Takaaki Higashihara' ${ }^{1}$, Akira Okada ${ }^{1,2^{*}}$ D, Taiko Kusano ${ }^{1}$, Kazuyoshi Ishigaki ${ }^{3}$, Akira Shimizu ${ }^{4}$ and Hideki Takano ${ }^{1}$
}

\begin{abstract}
Background: A pathergy reaction is defined as a hyperreactivity of the skin in response to minimal trauma, which is important in the diagnosis of Behçet's disease (BD). However, a pathergy reaction may not be restricted to the skin, and little is known about whether an invasive medical procedure can induce the reaction. Here we present a pathergy reaction induced by renal biopsy, an invasive procedure.

Case presentation: A 46-year-old man who was diagnosed with IgA vasculitis (IgAV) at the age of 38 was treated with prednisolone and mizoribine. However, complications such as common carotid arteritis or recurrent oral ulcer suggested the possibility of another pathophysiology. Later, increasing urine protein developed, suggesting disease aggravation. However, renal biopsy showed arteriosclerotic changes caused mainly by hypertension, negating exacerbation. After renal biopsy, his renal dysfunction and body temperature fluctuated, and detailed examinations revealed recurrent oral and genital ulcers and a folliculitis-like rash on his scrotum. Later, he complained of myodesopsia caused by hemorrhage in the ocular fundus due to occlusive vasculitis. Complete BD was diagnosed after development of the symptoms, and he was treated with prednisolone and colchicine.

Conclusion: Co-occurrence of $\mathrm{BD}$ with IgAV is very rare and may be associated with immune disorders. Interestingly, a renal biopsy revealed $\mathrm{BD}$, which was masked by the presence of IgAV, and elucidated the etiology of the unexplainable symptoms. To the best of our knowledge, this is the first report of renal pathergy. This case enlightens clinicians to the fact that not only a needle stimulation but also an invasive procedure can cause a pathergy reaction.
\end{abstract}

Keywords: IgA vasculitis, Henoch-Schönlein purpura, Behçet's disease, IgA nephritis, Renal biopsy, Pathergy reaction, HLA-B51

\section{Background}

Behçet's disease (BD) is characterized by recurrent oral and genital ulceration, ocular disease, and several systemic manifestations, including skin lesions, gastrointestinal involvement, neurologic disease, vascular disease, and arthritis [1]. BD can involve blood vessels of all sizes; hence, most of its clinical manifestations are caused by vasculitis [2]. In 1963, the first occurrence of proteinuria

\footnotetext{
* Correspondence: aokada-tky@umin.ac.jp

'Department of Nephrology, Tokyo Teishin Hospital, 2-14-23, Fujimi, Chiyoda-ku 102-8798, Tokyo, Japan

${ }^{2}$ Divison of Nephrology and Endocrinology, The University of Tokyo Graduate School of Medicine, 7-3-1, Hongo, Bunkyo-ku 113-8655, Tokyo, Japan

Full list of author information is available at the end of the article
}

and hematuria was reported in 13 of $65 \mathrm{BD}$ patients [3]. Thereafter, many reports showed renal involvement with BD $[4,5]$. The association with IgA vasculitis (IgAV) and $\mathrm{BD}$ is not clear [6-9]; few reports have shown a pathergy reaction activated at other tissue sites [10], and we experienced a rare case of pathergy reaction induced by renal biopsy, an invasive procedure. To our knowledge, this is the first report of a BD patient who experienced a renal pathergy reaction.

\section{Case presentation}

A 46-year-old male was first referred to a nephrologist at the age of 15 years due to proteinuria and hematuria. Renal biopsy revealed IgA nephritis (IgAN). At 38 years, his history of IgAN was complicated with abdominal 
pain and painful palpable purpura on his lower legs. A skin biopsy revealed leukocytoclastic vasculitis. Thus, he was diagnosed as having Henoch-Schönlein purpura (IgAV). On the other hand, some of his complications were unexplainable by the original disease alone, such as common carotid arteritis and recurrent oral ulcer. Although he was diagnosed with steroid-induced diabetes mellitus at the age of 40, it was under control with HbA1c levels approximately $7 \%$ on average; furthermore, multiple examinations by an ophthalmologist revealed no diabetic retinopathy. As a treatment for IgAV, oral prednisolone (PSL) was started at $50 \mathrm{mg} /$ day, and his purpura and urine abnormalities resolved; PSL dose was gradually reduced.

IgAV relapsed at the age of 45 with increasing urine protein. Tonsillectomy plus triple methylprednisolone pulse therapy did not ameliorate the urine protein aggravation. Renal biopsy was performed and light microscopic analysis of the specimen revealed 14 glomeruli; of these, 2 were obsolescent, 4 were adherence lesions with fibrous crescents showing previous active IgAV, and the others exhibited only minor glomerular abnormalities. Immunofluorescence staining was negative for IgA or C3 in the glomeruli, and electron microscopy revealed no evidence of an early sign of diabetic nephropathy such as diffuse thickening of glomerular basement membrane. As a result, no exacerbation of the original disease and no onset of other specific kidney lesions, such as diabetic nephropathy, were observed (Figs. 1 and 2).
After the biopsy, intermittent fever developed and the serum creatinine temporally changed from 0.68 to $2.26 \mathrm{mg} / \mathrm{dl}$. In addition, a prolonged fever necessitated a detailed laboratory analysis (Table 1). Microbacterial and imaging inspections, including Ga-scintigraphy, could not detect any inflammatory focus; however, a physical examination revealed a folliculitis-like rash on his scrotum (Fig. 3). Ophthalmologic examination and gastroscopy and colonoscopy tests yielded negative results. At first, we diagnosed an incomplete type of BD, which was treated with PSL. The increased dose of PSL failed to relieve the fever and finger pain, and then, an ophthalmologic reexamination revealed hemorrhage in the ocular fundus (Fig. 4). In addition to the absence of microaneurysms, local filling defects of the vein were seen at the area of retinal hemorrhage, suggesting BD-associated vasculitis. After the diagnosis of complete-type of $\mathrm{BD}$ was made, the PSL dose was increased to $30 \mathrm{mg}$ daily. Urinary protein levels subsequently improved along with amelioration of $\mathrm{BD}$, which supported that diabetes had little contribution to the renal lesion, considering the absence of diabetic retinopathy and short history. Despite tapering of the PSL, no exacerbation was observed with the daily oral $8 \mathrm{mg}$ of PSL and $1 \mathrm{mg}$ of colchicine.

\section{Conclusions}

$\mathrm{BD}$ is a recurrent multisystem inflammatory disorder characterized by vasculitis and arteritis $[1,2]$ and involves blood vessels of all sizes [11-13]. Conversely,

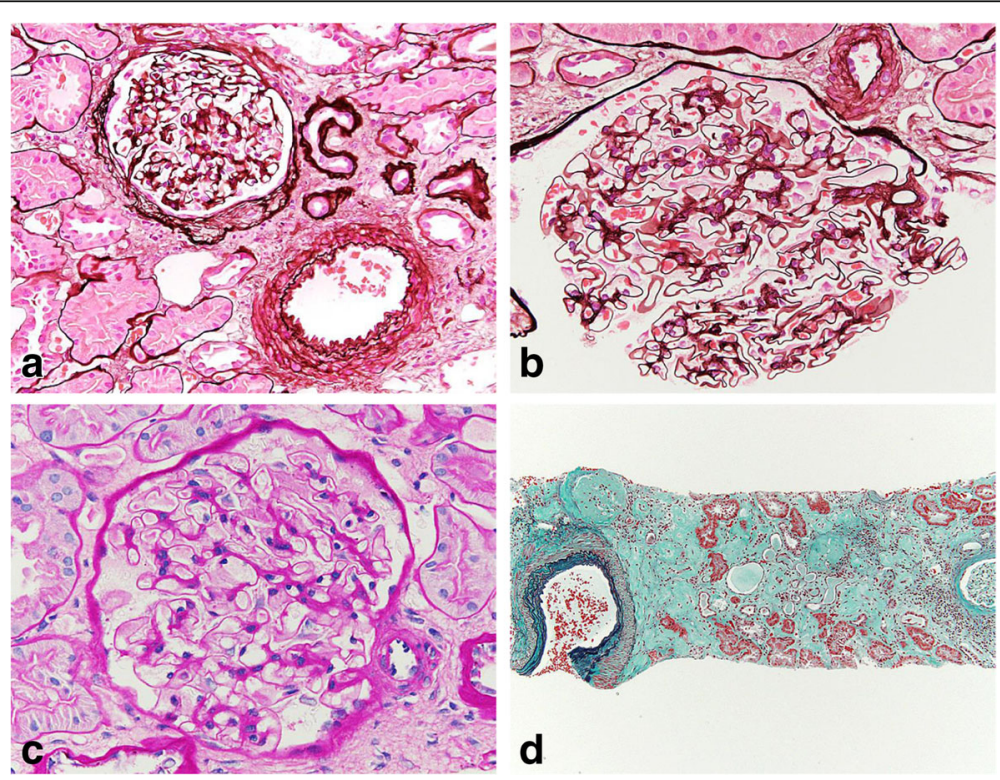

Fig. 1 Light microscopic images of renal biopsy. a The biopsy highlighted 14 glomeruli, of which two were obsolescent, four were adherence lesions with fibrous crescents showing previous active IgA vasculitis (periodic acid-silver methenamine stain; original magnification, $\times 200$ ). $\mathbf{b}$, c Other glomeruli showed little hypertrophy and minor glomerular abnormalities (b periodic acid-silver methenamine stain; $\mathbf{c}$ Periodic acid-Schiff stain; original magnification, $\times 600$ ). $\mathbf{d}$ Tubulointerstitial atrophy developed and showed an arteriosclerotic lesion with hypertension and diabetes (Masson trichrome stain; original magnification, $\times 40$ ) 

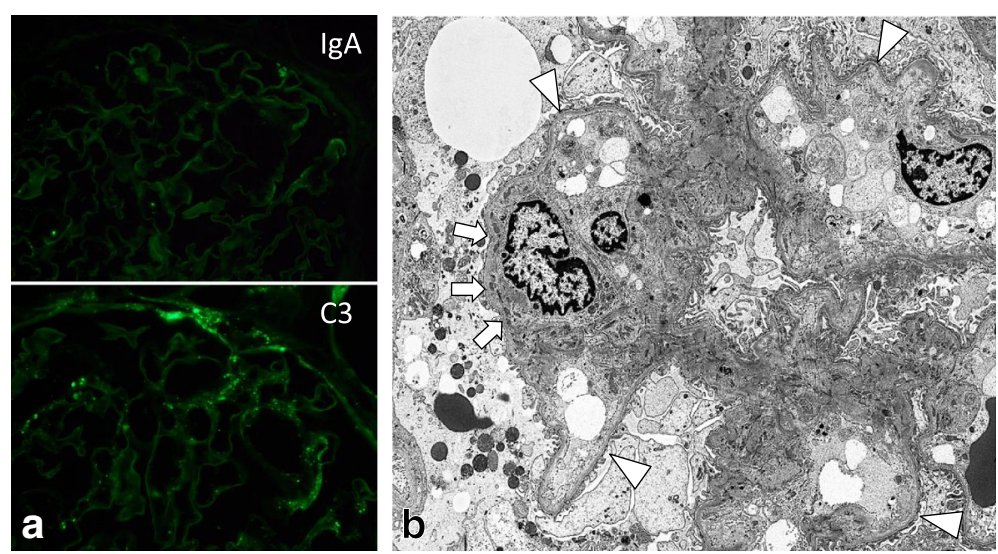

Fig. 2 Immunofluorescence staining and electron microscopy of the renal biopsy. a Immunofluorescence staining for IgA and C3 showed negative staining in the glomeruli (original magnification, $\times 600$ ). $\mathbf{b}$ Electron microscopy revealed small electron-dense deposits (arrows) under the basement membrane. In addition, diffuse thickening of glomerular basement membrane (GBM), which is known as an early ultrastructural characterization of diabetic nephropathy, was not detected (sites of GBM not affected pointed in arrowheads) (original magnification, $\times 4000$ )

IgAV is defined as vasculitis with IgA1-dominant immune deposits; it affects small vessels, skin, and the gastrointestinal tract and causes arthritis [14]. In this case, IgAV caused abdominal pain and painful palpable purpura; however, the patient presented at the same time with bilateral common carotid arteritis on carotid ultrasonography. The latter is explained by coexistence of $\mathrm{BD}$, which can affect large arteries. In addition, he also had recurrent oral ulcers before the diagnosis of IgAN, which also supports the coexistence of the two diseases. However, the activity of $\mathrm{BD}$ was suppressed by steroid therapy as an IgAV treatment but was coincidentally activated by a pathergy reaction, which was identified during a renal biopsy.
A pathergy reaction is defined as hyperreactivity of the skin in response to minimal trauma [15]. This is important in the diagnosis of $\mathrm{BD}$ and is assigned 1 point based on the International Criteria for BD, which classifies a patient scoring $\geq 4$ points as having $\mathrm{BD}[16]$. The pathergy reaction was not restricted to the skin [10]; it also may be associated with superficial thrombophlebitis induced by venipuncture $[17,18]$, an erythematous lesion on the conjunctiva after intravitreal corticosteroid injections [19], anastomotic ulcers after surgical treatment of intestinal lesions [20], and aneurysm after vascular surgery [21, 22]. We could not confirm a clear presentation of inflammation on the puncture site in our case; however, renal biopsy activated a pathergy reaction in the kidney, which

Table 1 Laboratory tests

\begin{tabular}{|c|c|c|c|c|c|}
\hline \multicolumn{2}{|c|}{ Blood test } & \multirow{2}{*}{$\begin{array}{l}\text { Y-glutamyl transferase } \\
\text { Fasting blood glucose }\end{array}$} & \multirow{2}{*}{$\begin{array}{l}25 \mathrm{IU} / \mathrm{l} \\
117 \mathrm{mg} / \mathrm{dl}\end{array}$} & \multirow{2}{*}{$\begin{array}{l}\text { anti-dsDNA } \\
\text { MPO-ANCA }\end{array}$} & \multirow{2}{*}{$\begin{array}{l}\text { Negative } \\
\text { Negative }\end{array}$} \\
\hline White blood cells & $10,800 / \mu l$ & & & & \\
\hline Hemoglobin & $11.6 \mathrm{~g} / \mathrm{dl}$ & Hemoglobin A1c & $7.4 \%$ & PR3-ANCA & Negative \\
\hline Platelets & $38.3 \times 10^{4} / \mu \mathrm{l}$ & APTT & $23.9 \mathrm{~s}$ & anti-GBM & Negative \\
\hline Sodium & $137.1 \mathrm{mEq} / \mathrm{L}$ & PT-INR & 1.05 & HIV & Negative \\
\hline Potassium & $3.6 \mathrm{mEq} / \mathrm{L}$ & FDP & $5.2 \mu \mathrm{g} / \mathrm{ml}$ & HCV antibody & Negative \\
\hline Chloride & $100.5 \mathrm{mEq} / \mathrm{L}$ & C-reactive protein & $1.87 \mathrm{mg} / \mathrm{dl}$ & HBs antigen & Negative \\
\hline Calcium & $9.0 \mathrm{mg} / \mathrm{dl}$ & ESR & $101 \mathrm{~mm} / \mathrm{h}$ & TPHA & Negative \\
\hline Phosphate & $2.3 \mathrm{mg} / \mathrm{dl}$ & $\lg A$ & 330 mg/dl & \multicolumn{2}{|c|}{ Urine test } \\
\hline Creatinine & $0.74 \mathrm{mg} / \mathrm{dl}$ & $\lg G$ & 948 mg/dl & $\mathrm{pH}$ & 6.0 \\
\hline Urea Nitrogen & $7.6 \mathrm{mg} / \mathrm{dl}$ & $\lg M$ & 87 mg/dl & Occult blood & Negative \\
\hline Total protein & $6.6 \mathrm{~g} / \mathrm{dl}$ & $\lg \mathrm{E}$ & $48 \mathrm{IU} / \mathrm{ml}$ & Glucose & Negative \\
\hline Albumin & $3.2 \mathrm{~g} / \mathrm{dl}$ & $\mathrm{C} 3 \mathrm{C}$ & 159 mg/dl & White blood cells & Negative \\
\hline Lactate dehydrogenase & $181 \mathrm{IU} / \mathrm{l}$ & C4 & $51 \mathrm{mg} / \mathrm{dl}$ & Urine protein & $1.01 \mathrm{~g} / \mathrm{gCr}$ \\
\hline Aspartate aminotransferase & $16 \mathrm{IU} / \mathrm{I}$ & $\mathrm{CH} 50$ & $83 \mathrm{U} / \mathrm{ml}$ & NAG & $15.1 \mathrm{U} / \mathrm{l}$ \\
\hline Alanine aminotransferase & $25 \mathrm{IU} / \mathrm{I}$ & Anti-nuclear antibody & Negative & $\beta 2-M G$ & $1102 \mathrm{ng} / \mathrm{ml}$ \\
\hline
\end{tabular}



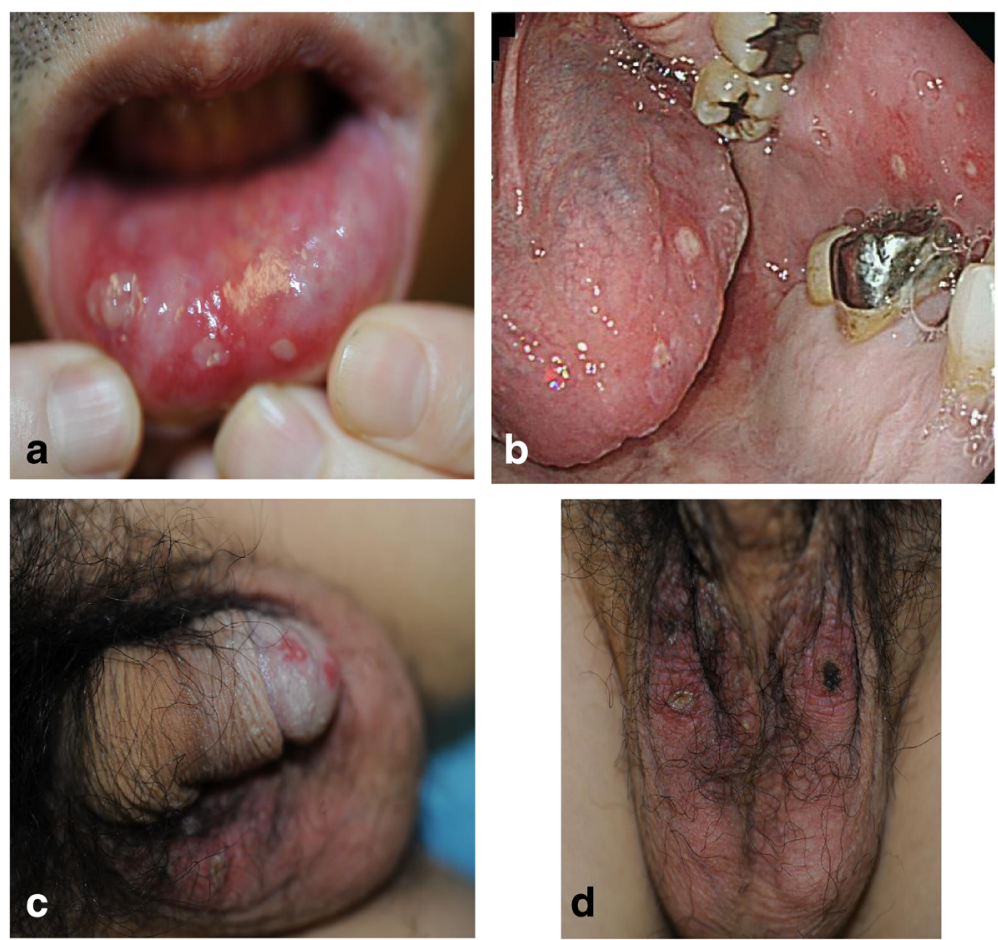

Fig. 3 Physical examination. a Ulcers on the lower lip. b Ulcers on the tongue and buccal mucosa. c Genital ulcers. d Folliculitis-like rash on the scrotum

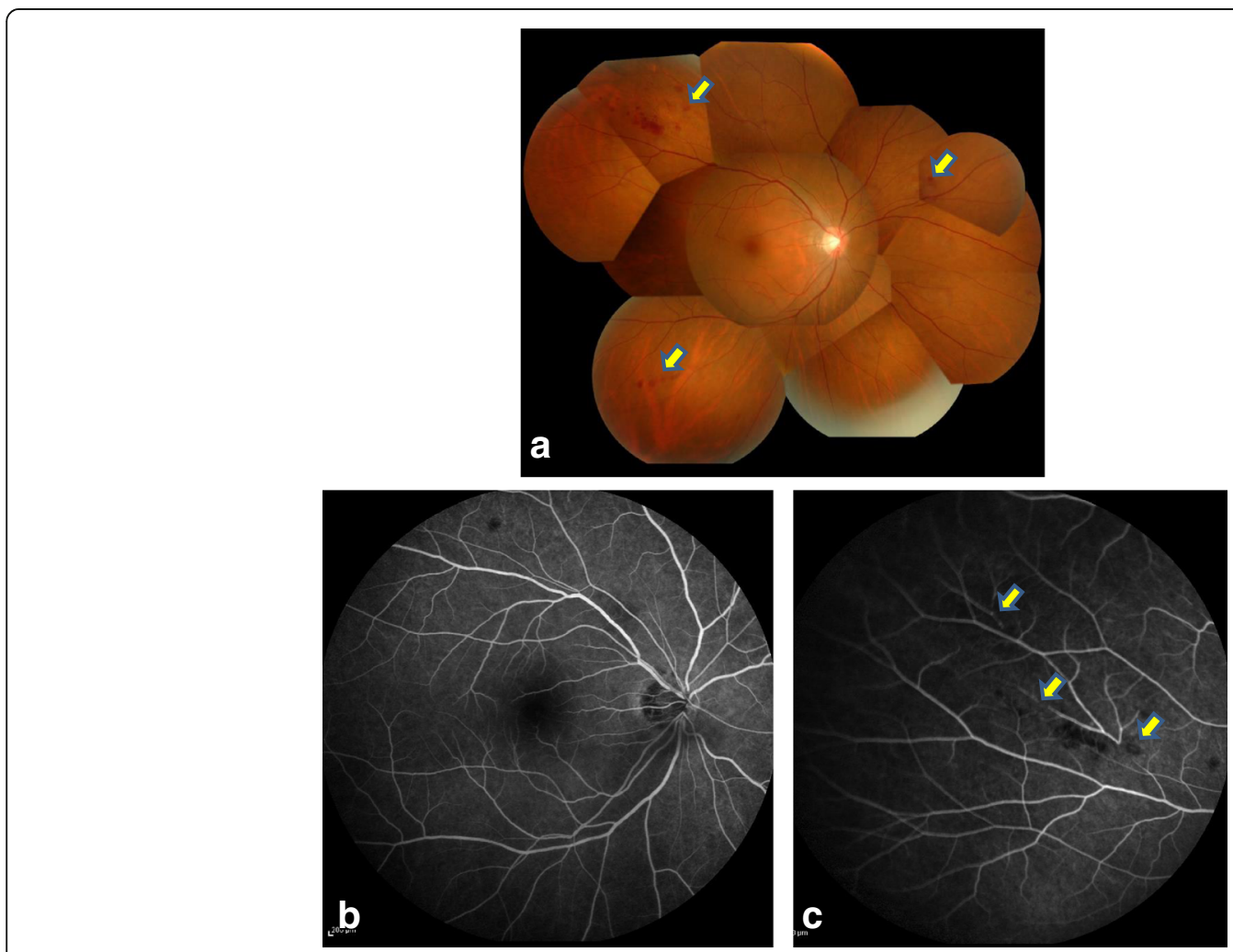

Fig. 4 Ophthalmologic examination. a Fundus examination: hemorrhage in the peripheral retina (arrows). b, c Fluorescent fundus angiography. There was no microaneurysm seen in diabetic retinopathy. The area of retinal hemorrhage and local filling defect of the vein are indicated by arrows 
is rich in blood vessels. We found that a renal biopsy itself can reveal another vasculitis complication.

Albeit rarely, BD can complicate IgAV or IgAN; only a limited number of articles have been reported $[6-9,23,24]$; thus, there may be something unusual about the coexistence. BD with renal involvement can present in certain human leukocyte antigens (HLA) differently from $\mathrm{BD}$ without renal involvement. Interestingly, previous studies have reported that only one of seven BD patients with renal involvement had HLA-B51 [25], which is associated with an increased risk of developing BD [26], while HLA-A2, A11, and particularly B35 are associated with an increased risk of IgAV [27]. The HLA types of blood lymphocytes in our patient were A2, B35, B48, DR8, and DR12, which suggests a high possibility of developing IgAV; however, our patient did not have HLA-B51. A negative finding for HLA-B51, as observed in our case, also may be a characteristic in BD patients with renal involvement, and thus, HLA-B51 may not be helpful in diagnosing $\mathrm{BD}$ with renal lesions.

BD can be diagnosed only by detailed physical examination; however, this is difficult when it is not suspected or masked by presentation of other forms of vasculitis or during immunosuppression treatment. Surprisingly, a renal biopsy disclosed "masked" BD by inducing a renal pathergy reaction; therefore, the etiology of common carotid arteritis and recurrent oral ulcer was unveiled because IgAV usually does not affect middle or large sized arteries. If it had not been for the renal biopsy, we may have failed to diagnose or treat the patient's coexisting BD. This case suggested that we should perform focused history-taking and physical examinations when some signs and symptoms in a patient cannot be explained fully by one form of vasculitis, for example, IgAV.

\section{Abbreviations}

ANCA: Anti-neutrophil cytoplasmic antibody: APTT: Activated partial thromboplastin time; BD: Behçet's disease; ESR: Blood sedimentation rate; FDP: Fibrin degradation products; HIV: Human immunodeficiency virus: HLA: Human leukocyte antigens; HSP: Henoch-Schönlein purpura; IgAN: IgA nephritis; IgAV: IgA vasculitis; MPO: Myeloperoxidase; NAG: N-acetyl-Dglucosamine; PR3: Proteinase-3; PSL: Prednisolone; PT-INR: Prothrombin timeinternational normalized ratio; RH: Retinal hemorrhage; TPHA: Treponema pallidum hemagglutination test; $\beta 2$-MG: $\beta 2$-microglobulin

\section{Acknowledgements}

None.

\section{Funding}

This study was partly supported by department fund.

\section{Availability of data and materials}

The dataset supporting the conclusions of this article is included within the article.

\section{Authors' contributions}

$\mathrm{TH}$ and $\mathrm{AO}$ wrote the manuscript and was a treating physician for the patient. TK, and $\mathrm{HT}$ also were treating physicians for the patient and assisted in drafting the manuscript. Kl analyzed the clinical course and helped draft the manuscript. AS performed a pathologic analysis and interpretation. All authors read and approved the final manuscript.

\section{Competing interests}

The authors declare that they have no competing interests.

\section{Consent for publication}

Written informed consent was obtained from the patient for publication of this case report and images in it. A copy of the written consent is available for review by the Editor of this journal.

Ethics approval and consent to participate

The authors adhered to CARE guidelines/methodology.

\section{Financial disclosure}

The authors declare that they have no relevant financial interests.

\section{Support}

None.

\section{Author details}

'Department of Nephrology, Tokyo Teishin Hospital, 2-14-23, Fujimi, Chiyoda-ku 102-8798, Tokyo, Japan. ${ }^{2}$ Divison of Nephrology and Endocrinology, The University of Tokyo Graduate School of Medicine, 7-3-1, Hongo, Bunkyo-ku 113-8655, Tokyo, Japan. ${ }^{3}$ Department of Allergy and Rheumatology, The University of Tokyo Graduate School of Medicine, 7-3-1, Hongo, Bunkyo-ku 113-8655, Tokyo, Japan. ${ }^{4}$ Department of Analytic Human Pathology, Graduate School of Medicine, Nippon Medical School, 1-1-5, Sendagi, Bunkyo-ku 113-8603, Tokyo, Japan.

Received: 6 June 2016 Accepted: 16 January 2017

Published online: 28 January 2017

\section{References}

1. International Study Group for Behcet's Disease. Criteria for diagnosis of Behcet's disease. Lancet. 1990;335(8697):1078-80.

2. Sobel JD, Tabori S, Tatarski I. Fibrinolysis and thrombosis in Behcet's disease. Dermatologica. 1974;148(2):93-7.

3. Oshima Y, Shimizu T, Yokohari R, Matsumoto T, Kano K, Kagami T, Nagaya H. Clinical studies on Behcet's syndrome. Ann Rheum Dis. 1963;22(1):36-45.

4. Akpolat T, Akkoyunlu M, Akpolat I, Dilek M, Odabas AR, Ozen S. Renal Behcet's disease: a cumulative analysis. Semin Arthritis Rheum. 2002;31(5):317-37

5. Akpolat T, Dilek M, Aksu K, Keser G, Toprak O, Cirit M, Oguz Y, Taskapan H, Adibelli Z, Akar H, et al. Renal Behcet's disease: an update. Semin Arthritis Rheum. 2008;38(3):241-8.

6. Furukawa T, Hisao O, Furuta S, Shigematsu H. Henoch-schonlein purpura with nephritis in a patient with Behcet's disease. Am J Kidney Dis. 1989; 13(6):497-500

7. Golan G, Beeri R, Mevorach D. Henoch-schonlein purpura-like disease representing a flare of Behcet's disease. Br J Rheumatol. 1994;33(12):1198-9.

8. Tsubakimoto A. A case of Behcet's disease associated with anaphylactoid purpura. Hihu. 1997;39(4):409-13. in Japanese.

9. Park YW, Park JJ, Lee JB, Lee SS. Development of henoch-schonlein purpura in a patient with Behcet's disease presenting with recurrent deep vein thrombosis. Clin Exp Rheumatol. 2007;25(4 Suppl 45):S96-8.

10. Sequeira FF, Daryani D. The oral and skin pathergy test. Indian J Dermatol Venereol Leprol. 2011;77(4):526-30.

11. Ehrlich GE. Vasculitis in Behcet's disease. Int Rev Immunol. 1997:14(1):81-8.

12. Takeno M, Sakane T. Vascular involvement in Behcet's disease. Intern Med. 2001;40(1):3-4.

13. Demirelli S, Degirmenci H, Inci S, Arisoy A. Cardiac manifestations in Behcet's disease. Intractable Rare Dis Res. 2015;4(2):70-5.

14. Jennette JC, Falk RJ, Bacon PA, Basu N, Cid MC, Ferrario F, Flores-Suarez LF, Gross WL, Guillevin L, Hagen EC, et al. 2012 revised International Chapel Hill consensus conference nomenclature of vasculitides. Arthritis Rheum. 2013;65(1):1-11.

15. Varol A, Seifert $O$, Anderson CD. The skin pathergy test: innately useful? Arch Dermatol Res. 2010;302(3):155-68.

16. The International Criteria for Behcet's Disease (ICBD). International team for the revision of the international criteria for Behcet's D: a collaborative study 
of 27 countries on the sensitivity and specificity of the new criteria. J Eur Acad Dermatol Venereol. 2014;28(3):338-47.

17. Sarica-Kucukoglu R, Akdag-Kose A, Kayabal IM, Yazganoglu KD, Disci R, Erzengin D, Azizlerli G. Vascular involvement in Behcet's disease: a retrospective analysis of 2319 cases. Int J Dermatol. 2006;45(8):919-21.

18. Calamia KT, Schirmer M, Melikoglu M. Major vessel involvement in Behcet's disease: an update. Curr Opin Rheumatol. 2011;23(1):24-31.

19. Yalcindag FN, Batioglu F. Pathergy-like reaction following intravitreal triamcinolone acetonide injection in a patient with Behcet disease. Ocul Immunol Inflamm. 2008;16(4):181-3.

20. Choi IJ, Kim JS, Cha SD, Jung HC, Park JG, Song IS, Kim CY. Long-term clinical course and prognostic factors in intestinal Behcet's disease. Dis Colon Rectum. 2000;43(5):692-700.

21. Alpagut U, Ugurlucan M, Dayioglu E. Major arterial involvement and review of Behcet's disease. Ann Vasc Surg. 2007;21(2):232-9.

22. Tuzun H, Besirli K, Sayin A, Vural FS, Hamuryudan V, Hizli N, Yurdakul S, Yazici H. Management of aneurysms in Behcet's syndrome: an analysis of 24 patients. Surgery. 1997;121(2):150-6

23. Altay M, Secilmis S, Unverdi S, Ceri M, Duranay M. Behcet's disease and IgA nephropathy. Rheumatol Int. 2012;32(7):2227-9.

24. Cho SB, Kim J, Kang SW, Yoo TH, Zheng Z, Cho S, Lee HS, Bang D. Renal manifestations in 2007 Korean patients with Behcet's disease. Yonsei Med J. 2013;54(1):189-96.

25. Zheng W, Li G, Zhou M, Chen L, Tian X, Zhang F. Renal involvement in Chinese patients with Behcet's disease: a report of 16 cases. Int J Rheum Dis. 2015;18(8):892-7.

26. de Menthon M, Lavalley MP, Maldini C, Guillevin L, Mahr A. HLA-B51/B5 and the risk of Behcet's disease: a systematic review and meta-analysis of casecontrol genetic association studies. Arthritis Rheum. 2009;61(10):1287-96.

27. Peru H, Soylemezoglu O, Gonen S, Cetinyurek A, Bakkaloglu SA, Buyan N, Hasanoglu E. HLA class 1 associations in henoch-schonlein purpura: increased and decreased frequencies. Clin Rheumatol. 2008;27(1):5-10

\section{Submit your next manuscript to BioMed Central and we will help you at every step:}

- We accept pre-submission inquiries

- Our selector tool helps you to find the most relevant journal

- We provide round the clock customer support

- Convenient online submission

- Thorough peer review

- Inclusion in PubMed and all major indexing services

- Maximum visibility for your research

Submit your manuscript at www.biomedcentral.com/submit
Biomed Central 